1. MBBS, DCP, M.Phil (Morbid Anatomy and Histopathology) Associate Professor

Department of Pathology Multan Medical \& Dental College, Multan.

2. MBBS

Ex. Resident

Department of Pathology

Post Graduate Medical Institute,

Lahore.

3. MBBS, MD

Consultant

Department of Pathologist

Morristown, Overlook and Newton Medical Centers

Atlantic Consolidated Laboratory 100 The American Road, Morris

Plains, NJ 07950

Correspondence Address:

Dr. Afra Samad

House No.68. Street No. 2 .

Mehrban Colony. Near MDA Chowk.

Multan.

afrasamad@yahoo.com

Article received on:

07/07/2018

Accepted for publication:

15/12/2018

Received after proof reading:

23/02/2019

\section{COLLISION TUMOUR IN OVARY;}

CASE REPORT: RARE CASE OF COLLISION TUMOUR IN OVARY: COMBINATION OF SEROUS CYSTADENOMA, FIBROMA AND BRENNER TUMOUR.

\begin{abstract}
Afra Samad', Namra Mahmood ${ }^{2}$, Arbaz Samad ${ }^{3}$
ABSTRACT: Most of the ovarian tumours are of surface epithelium and account for $65-75 \%$ of tumours. ${ }^{1}$ Serous cystadenoma constitutes $20 \%$ of ovarian tumours. Sex- cord stromal tumour is less common. Fibroma is the most common sex-cord stromal tumor comprising $70 \%{ }^{2}$ Tumors can present in a combination in ovary like teratoma and mucinous cystadenoma, granulosa cell tumour and mature teratoma and/or mucinous tumors. ${ }^{3}$ We report a rare case of combined serous cystadenoma and fibroma in a 55 years old female. Review of literature reveal only two such cases. To best of our knowledge this is the third case which is being report.
\end{abstract}

Key words: $\quad$ Collision Tumour, Fibroma, Serous Cystadenoma.

Article Citation: Samad A, Mahmood N, Samad A. Collision tumour in ovary; case report: rare case of collision tumour in ovary: combination of serous cystadenoma, fibroma and brenner tumour. Professional Med J 2019; 26(3):520-522. DOI: 10.29309/TPMJ/2019.26.03.3260

\section{INTRODUCTION}

Among ovarian epithelial tumors, serous cystadenomas are the most common and can be bilateral in up to $20 \%$ of the cases. Serous tumors with fibrous component are designated serous cystadenofibromas. Approximately $8 \%$ of all ovarian tumors are sex cord stromal tumours. They can occur in all age groups but predominantly affects perimenopausal women. Mostly they are benign. ${ }^{4}$

Brenner tumours constitute 2 to $3 \%$ of surface epithelial tumours. ${ }^{5}$ In most cases they are incidental findings. The significance of which is unknown. They can occur in association with other tumours like serous cystadenofibroma, mucinous cystadenoma and mature cystic teratoma. ${ }^{6}$

\section{Case Presentation}

Our patient was a 55 years old female presented with abdominal pain for 15 days. On ultrasonography bilateral cystic and solid adnexal masses were seen. The patient underwent hysterectomy and bilateral salpingo- oophorectomy on gross examination, cut surface of the right ovary showed two small cysts measuring $1.0 \times 1.0 \mathrm{~cm}$ and $0.7 \times 0.6 \mathrm{~cm}$; containing gelatinous material. A white tan nodule measuring $3 \mathrm{~mm}$ was noted in the large cyst. Left ovarian mass measured $17 \times 13 \times 10.5 \mathrm{~cm}$. Cut surface showed white tan solid component in the lower half and cystic in the upper half. Cystic component measured $10.5 \times 6.0 \times 4.0 \mathrm{~cm}$ and was multiloculated with predominantly smooth inner lining and few gray white nodules measuring less than $1 \mathrm{~mm}$. Left ovary measured $5.0 \times 4.5 \times 2.5 \mathrm{~cm}$. Cervix, endomyometrium and both fallopian tubes were unremarkable on gross and microscopic examination. Hematoxylin and eosin stained sections of the right ovary showed cystic follicles and cyst lined by ciliated cuboidal to columnar epithelium consistent with serous cystadenoma.

Sections of the cystic area of the left ovarian mass also showed features of serous cystadenoma. Sections of the solid area showed bland appearing spindle cells separated by marked edema and myxoid change. The histological features from 
solid area were suggestive of fibroma. Sections of the residual left ovary revealed scattered clusters of transitional type epithelium consistent with brenner tumor. The final report was bilateral serous cystadenoma, left fibroma and Brenner tumour.

This is a case of rare collision tumour in ovary. Collision tumours are the tumours having two distinct histological types in the same organ. These types of collision tumour are quite rare in ovaries. $^{3}$

Ovarian tumours show different pattern of histology reflecting their different cell of origin. ${ }^{7}$

The most frequently cited combination in ovary is that of Brenner tumour with Mature cystic teratoma and sertoli leydig cell tumour with mucinous cystadenoma. ${ }^{8}$

In some cases the serous cystadenoma may have fibrous component in it and it is designated as serous cystadenofibroma. As both the components are intermixed. ${ }^{9}$

But in our case both the cystic and solid components are grossly and histologically separate. Although, some of the fibromas may show cystic degeneration but in that case the cyst has no lining whereas in our case the cyst was lined by serous epithelium. ${ }^{10}$ Also careful examination of multiple sections is required to rule out stromal overgrowth in Brenner tumour which presents as a single nodule with small foci of transitional epithelium scattered within the stroma. ${ }^{11}$

\section{CONCLUSION}

The final diagnosis was the collision tumour of the left ovary having serous cystadenoma, fibroma and brenner tumour. The right ovary had serous cystadenoma.

\section{Conflicts of Interest}

No potential conflict of interest relevant to this article was reported.

Copyright@ 15 Dec, 2018.

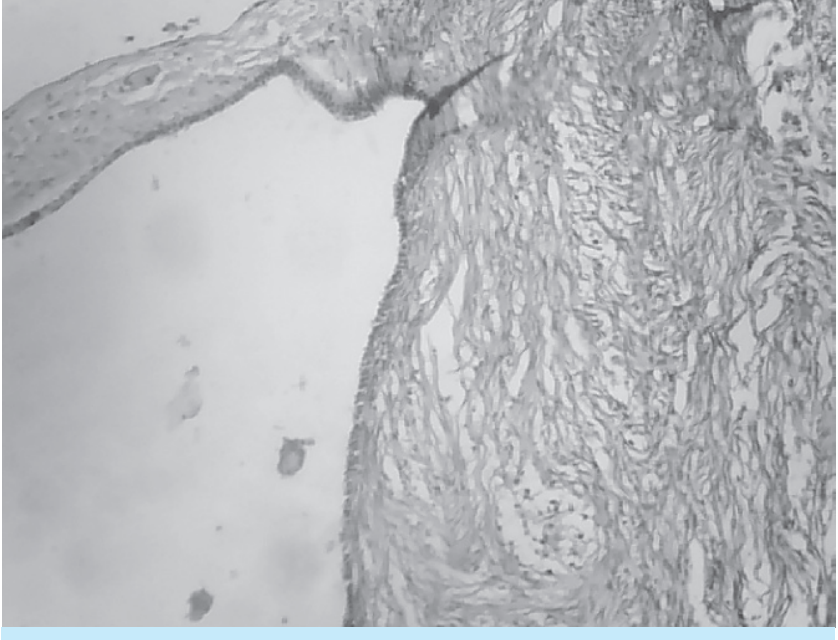

Figure-1. Serous cystadenoma of right ovary (magnification 100x).

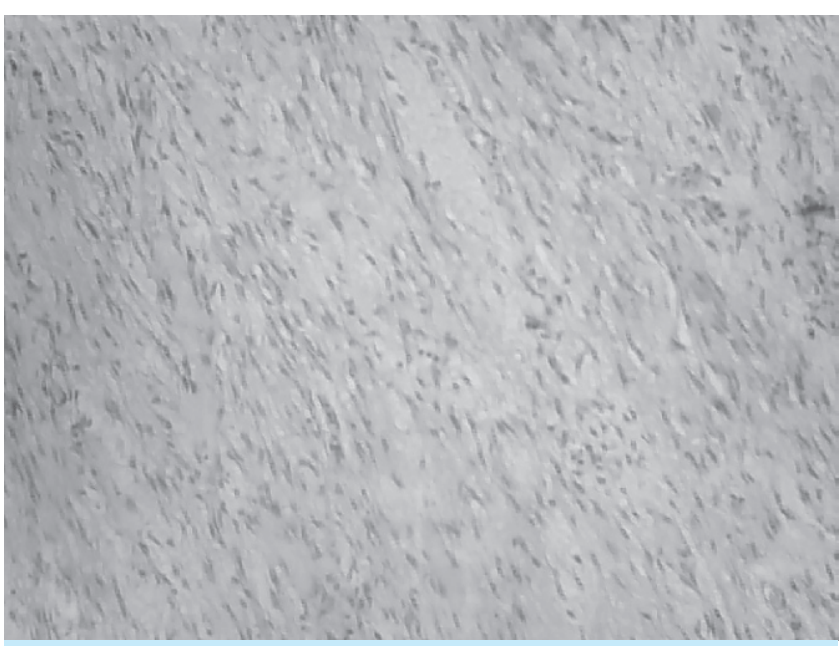

Figure-2. Spindle shaped cells separated by edema and myxoid change (Fibroma) of left ovary (magnification 100x).

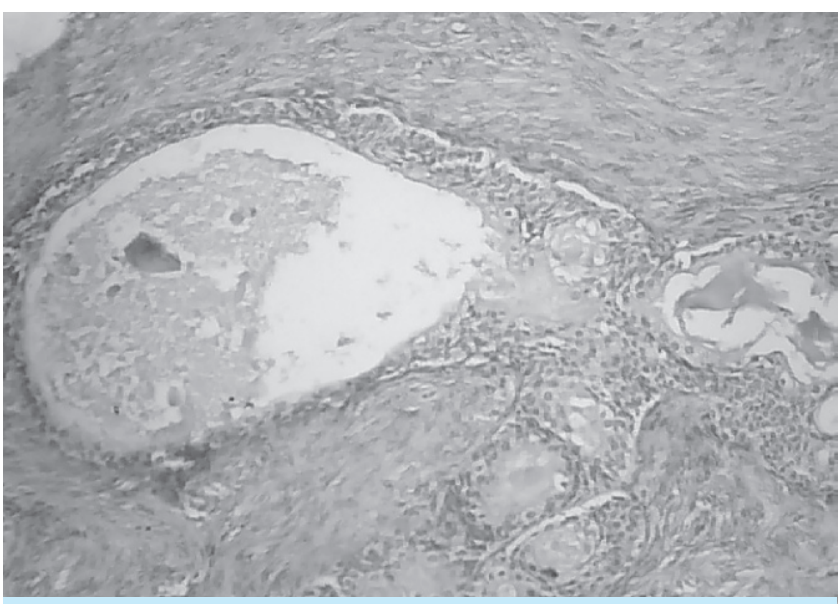

Figure-3. Focus of Brenner tumour of left ovary (magnification 100x). 


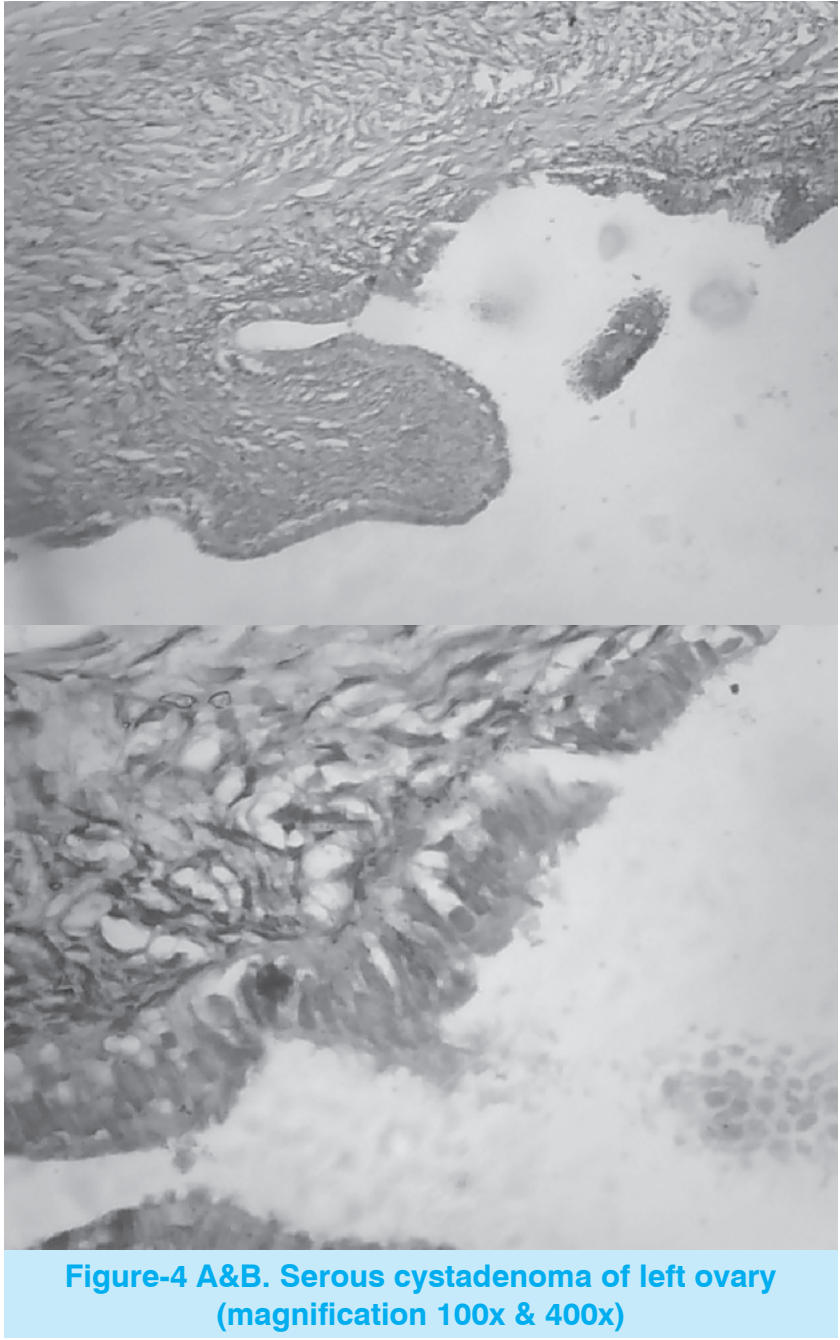

\section{REFERENCES}

1. Petros M, Koliba P, Sevcik L, Curik R. Giant benign mucinous cystadenoma of both ovaries in early puerperium: Case report and review of literature. Ceska gynekol 2005; 70:156-8.

2. Human Reproduction. University of Utah Medpath http://library.med.utah.edu/kw/human-reprod/ seminars/seminar 4 B2.html.

3. Bige O, Demir A, Koyuncuoglu M, Secil M, Ulukus C. Saygili U. Collision tumour: Serous cystadenoma and dermoid cyst in the same ovary. Arch Gynecol Obstet 2009; 279:767-70.

4. Young RH. In: Ronett BM, Kurman RJ. Ellenson LH, eds. Blaustein's pathology of the female genital tract. $6^{\text {th }}$ ed. New York: Springer: 2011; 905-966.

5. Longacre TA, Gilks CB. Surface epithelial-stromal tumours of the ovary. In: Nucci MR, Oliva E, Goldbum JR, ed: Gynecologic Pathology. London: Churchill Livingstone Elsevier; 2009: 393-444.

6. Waxman M. Pure and mixed Brenner Tumors of the ovary; Clinicopathologic and histogenetic observations. Cancer. 1979; 43(5):1830-1839.

7. Perveen S, llyas N, Asghar S. Patterns of care for ovarian cancer: Patients at institute of Nuclear medicine and oncolosy (INMOL) Lahore. Specialist J Pak Med. Sci 1999; 15: 209-15.

8. Fox Hc and Wells M. Surface epithelial stromal tumors of the ovary. In: Haines \& Taylor Obstetrical and Gynaecological Pathology. H. Fox and M. Wells. Eds. Vol 1, Churchill Livingstone Madrid Spain, 2003.

9. Jayalakshmy PS, Poothiode U, Krishna G and Jayalakshmy PL. Ovarian fibroma with serous cystadenoma- An unusual combination: A case report. Case reports in Obstetrics and Gynecology. 2012.

10. Lee KR, Tavassoli FA, Prat $J$ etal. Surface epithelialstromal tumors. In pathology \& genetics of tumours of the breast and female genital organs, FA, Tavassoli A and P. Devilee, JARC Press Lyon, France; 2003:124.

11. Ross JA and Saglam O. Stromal overgrowth in a Brenner Tumour or ovarian fibroma with minor sex cord elements? Cancer Control Journal of the Moffitt Cancer Center. July 2015; vol.22.3:366-68.

\section{AUTHORSHIP AND CONTRIBUTION DECLARATION}

\begin{tabular}{|c|l|l|c|}
\hline Sr. \# & \multicolumn{1}{|c|}{ Author-s Full Name } & \multicolumn{1}{|c|}{ Contribution to the paper } & Author=s Signature \\
\hline 1 & Afra Samad & 1st Author & Afra Samad. \\
\hline 2 & Namra Mahmood & 2nd Author & \\
3 & Arbaz Samad & 3rd Author & \\
\hline
\end{tabular}

